\title{
The Diastolic Blood Pressure J-Curve in Hypertension Management: Links and Risk for Cardiovascular Disease
}

\author{
Brian Gaffney (D) \\ Alan P Jacobsen (iD ${ }^{2}$ \\ Abhishek W Pallippattu (D) \\ Niall Leahy (D) \\ John W McEvoy (D) \\ 'National Institute for Prevention and \\ Cardiovascular Health, National \\ University of Ireland Galway, School of \\ Medicine, Galway, Ireland; ${ }^{2}$ Ciccarone \\ Center for the Prevention of \\ Cardiovascular Disease, Division of \\ Cardiology, Department of Medicine, \\ Johns Hopkins Medical Institutions, \\ Baltimore, MD, USA
}

Purpose of Review: The treatment of hypertension has changed dramatically over the last century, with recent trials informing clinical guidelines that recommend aiming for lower blood pressure (BP) targets than ever before. However, a "J"- or "U-shaped curve" in the association between diastolic BP and cardiovascular events has been observed in epidemiological studies, suggesting that both high diastolic BPs and diastolic BPs below a certain nadir are associated with higher risk of cardiovascular disease (CVD) events. Despite the potential for confounding and reverse causation, this association may caution against overly intensive BP lowering in some hypertensive adults who also have a low baseline diastolic BP.

Recent Findings: Recent post-hoc analyses of the landmark Systolic Blood Pressure Intervention Trial (SPRINT) appear to contradict these J-curve concerns, finding that the benefit of more intensive BP treatment did not differ based on baseline blood pressure. Similarly, sensitivity analyses of The Strategy of Blood Pressure Intervention in the Elderly Hypertensive Patients (STEP) randomized controlled trial found that patients experienced similar benefits from an intensive BP goal, regardless of whether their diastolic BP was above or below $60 \mathrm{~mm} \mathrm{Hg}$. Finally, several Mendelian randomization analyses, which are less susceptible to confounding and reverse causation, demonstrated a clear linear relationship between diastolic BP and cardiovascular events. These studies indicate that a potential reduction in CVD risk is possible, irrespective of baseline diastolic BP values.

Summary: Sufficient recent evidence indicates that low diastolic BP is not causal of worse cardiovascular outcomes but rather represents confounding or reverse causation. Therefore, while low diastolic BP can be considered a marker of CVD risk, this risk is not expected to increase with further BP lowering when necessary to control concomitant elevations of systolic BP. Indeed, BP reduction in this setting appears beneficial.

Keywords: diastolic blood pressure, cardiovascular disease, J-curve

\section{Introduction}

Hypertension is a major cause of premature death worldwide. ${ }^{1}$ It is a known risk factor for myocardial infarction (MI), stroke, chronic kidney disease (CKD) and, more recently, has been the most prevalent underlying medical condition in adults hospitalized with COVID-19.,3 Longitudinal and epidemiological studies have shown that hypertension is a major cause of cardiovascular disease (CVD)
Correspondence: John W McEvoy National Institute for Prevention and Cardiovascular Health, National University of Ireland Galway, Galway, Ireland

Tel +35391544310

Email johnwilliam.mcevoy@nuigalway.ie 
accounting for 9.4 million deaths and 9.3\% of global disability adjusted life-years. ${ }^{1,4-6}$ A large pooled-cohort analysis published in the Lancet in 2003 showed the epidemiologic risk of CVD increases above a blood pressure (BP) of $115 / 75 \mathrm{~mm} \mathrm{Hg}^{7}$ The most recent data now suggest that mortality risk from CVD events may increase linearly from BP levels as low as 90/75. ${ }^{8}$ While evidence from epidemiologic studies is important, guidelines have traditionally focused primarily on evidence from randomized clinical trials (RCTs) when deciding on both BP thresholds to define hypertension and BP targets for drug treatment. ${ }^{6}$ Consequently, guideline-based BP targets have reduced over time, reflecting a continually evolving evidence base on the topic. Current hypertension guidelines generally recommend more intensive BP control than ever before to reduce CVD events, aiming for target values as low as 130/80 $\mathrm{mm} \mathrm{Hg.}{ }^{2,4,9}$

Despite the overwhelming evidence for treating systolic BP to levels of $<130 \mathrm{~mm} \mathrm{Hg}$ in most adults, these targets are often not met. ${ }^{10}$ A systematic review of population-based studies in over 90 countries published in 2010 showed that fewer than half of patients with hypertension were aware of their diagnosis. ${ }^{1}$ Furthermore, 36.9\% were treated with antihypertensive medication and just $13.8 \%$ had their blood pressure within target. ${ }^{1}$ These numbers have undoubtedly worsened since the most recent American Heart Association/American College of Cardiology (AHA/ACC) and European Society of Cardiology (ESC) Hypertension guidelines, which lowered the BP threshold to define hypertension. ${ }^{2,9}$ Concern for iatrogenic harm in those with lower diastolic $\mathrm{BP}$, is one possible explanation for this poor attainment of BP goals. The observation that lower diastolic BP is associated with higher risk for CVD events and mortality - also known as the $\mathrm{J}$ or $\mathrm{U}$ Curve - is a potential cause for hesitation among physicians who are considering more intensive control of systolic BP in their patients. ${ }^{11-14}$ This differs from the relationship between systolic BP and CVD events where the "lower is better" paradigm tends to hold true and where most studies, with few exceptions, show a linear trend between lower systolic BP and reduced cardiovascular events, even for systolic BPs as low as $90 \mathrm{~mm} \mathrm{Hg}^{14-16}$

This review will focus on the evidence base for the J-curve and highlight the theory explaining why myocardial perfusion may be particularly susceptible to low diastolic BP. We will discuss the ESC guideline recommendation to avoid lowering diastolic BP beyond a threshold, in certain patients based on their comorbidities. We will then comment on how recent randomized trials and Mendelian randomization studies have provided crucial insight on the causal relationship - or lack thereof between low diastolic BP and cardiovascular events. Finally, we will suggest an approach to the hypertensive patient with low diastolic blood pressure (ie, isolated systolic hypertension with wide pulse pressure).

\section{Methods}

PubMed was used to identify relevant references using the title and abstract search terms "Blood Pressure" and "J-Curve" or "U-Curve". We also searched all the references in systematic reviews and meta-analyses on this topic. Only articles published in English between January 1970 and June 2021 were included in this narrative review.

\section{Evidence from Traditional Observational Studies}

In 1987, Cruickshank et al demonstrated a J-shaped relationship between diastolic BP and MI in those with evidence of ischemic heart disease (Table 1). ${ }^{17}$ These findings were corroborated by Farnett et al four years later, with a meta-analysis of 13 studies that found increased cardiac events with diastolic BP levels below $85 \mathrm{~mm} \mathrm{Hg} .{ }^{18}$ Over time, the nadir of diastolic BP tested in J-curve analyses has tended to fall, as evidence for more intensive treatment of hypertension has emerged (Figure 1). In 2006, a secondary analysis of data from the International Verapamil-Trandolapril Study (INVEST) looked at the incidence of cardiovascular morbidity and mortality with decreasing diastolic BP. ${ }^{19}$ The analysis found CVD events to be reduced to a nadir at a diastolic $\mathrm{BP}$ of $84 \mathrm{~mm} \mathrm{Hg}$. Below this value, a progressive increase in CVD events was seen, such that the primary outcome doubled for those with a diastolic BP $<70 \mathrm{~mm} \mathrm{Hg}$ and tripled for those with a diastolic BP $<60 \mathrm{~mm} \mathrm{Hg}$. The Treating to New Targets (TNT) Trial demonstrated greater efficacy in preventing cardiovascular events, with a higher dose of atorvastatin among patients with stable coronary artery disease and hyperlipidemia. ${ }^{20} \mathrm{~A}$ subsequent analysis in 2010 found that those with systolic BP $<110$ $120 \mathrm{~mm} \mathrm{Hg}$ and a diastolic BP $<60-70 \mathrm{~mm} \mathrm{Hg}$ were at increased risk of cardiovascular events, except for stroke. $^{21}$ 
Table I Selected Observational Data Demonstrating a Diastolic BP J-Curve

\begin{tabular}{|c|c|c|c|c|c|}
\hline Investigators & $\begin{array}{l}\text { Trial Data } \\
\text { Analysed }\end{array}$ & $\begin{array}{l}\text { Type of } \\
\text { Observational } \\
\text { Analysis }\end{array}$ & $\begin{array}{l}\text { Number of } \\
\text { Participants }\end{array}$ & $\begin{array}{l}\text { Nadir of } \\
\text { DBP } \\
\text { J-Curve } \\
\text { Reported }\end{array}$ & Inclusion and Exclusion Criteria \\
\hline $\begin{array}{l}\text { Cruickshank } \\
\text { et al } 1987^{17}\end{array}$ & $\begin{array}{l}\text { HTN clinic at } \\
\text { Clatterbridge } \\
\text { Hospital }\end{array}$ & $\begin{array}{l}\text { Prospective, } \\
\text { cohort }\end{array}$ & 932 & $90 \mathrm{mmHg}$ & $\begin{array}{l}\text { Included "all-comers" design, hypertensive patients. No } \\
\text { exclusion criteria }\end{array}$ \\
\hline $\begin{array}{l}\text { Farnett et al } \\
\left.199\right|^{18}\end{array}$ & I3 Studies & Meta-analysis & $>48,000$ & $85 \mathrm{mmHg}$ & $\begin{array}{l}\text { I } 3 \text { Studies selected from } 478 \text { indexed through MEDLINE } \\
\text { between } 1966 \text { and } 1989 \text {. Studies included had at least } \\
\text { I year of htn treatment, had MACE as the endpoint, } \\
\text { stratified to at least } 3 \text { levels of BP and were either } \\
\text { retrospective cohort or RCT }\end{array}$ \\
\hline $\begin{array}{l}\text { Messerli et al } \\
2006^{19}\end{array}$ & INVEST & $\begin{array}{l}\text { Retrospective } \\
\text { analysis of RCT }\end{array}$ & 22,576 & $84 \mathrm{mmHg}$ & $\begin{array}{l}\text { Included hypertensive patients with CAD over } 50 \text { yo. } \\
\text { Excluded MI within } 3 \text { months and class IV or V congestive } \\
\text { heart failure }\end{array}$ \\
\hline $\begin{array}{l}\text { Bangalore et al } \\
2010^{21}\end{array}$ & TNT & $\begin{array}{l}\text { Retrospective } \\
\text { analysis of RCT }\end{array}$ & $10,00 \mid$ & $81.4 \mathrm{mmHg}$ & $\begin{array}{l}\text { Included 35-75yo patients with CAD. Excluded statin } \\
\text { allergy, pregnant women, liver disease, nephrotic } \\
\text { syndrome, unstable angina, MI within I month, } \\
\text { malabsorption, malignancy, alcohol abuse and } \\
\text { uncontrolled hypertension, diabetes or hypothyroidism }\end{array}$ \\
\hline $\begin{array}{l}\text { Mancia et al } \\
201 I^{36}\end{array}$ & ONTARGET & $\begin{array}{l}\text { Retrospective } \\
\text { analysis of RCT }\end{array}$ & 31,546 & $72 \mathrm{mmHg}$ & $\begin{array}{l}\text { Included patients with known atherosclerotic disease or } \\
\text { diabetes. Excluded those with heart failure or } \\
\text { uncontrolled hypertension }(>\mid 60 / 100)\end{array}$ \\
\hline $\begin{array}{l}\text { Tsujimoto } \\
\text { et al } 2018^{24}\end{array}$ & TOPCAT & $\begin{array}{l}\text { Retrospective } \\
\text { analysis of RCT }\end{array}$ & 3417 & $70 \mathrm{mmHg}$ & $\begin{array}{l}\text { Included patients with known hypertension over } 50 \text { yo. } \\
\text { Excluded those with Ejection Fraction }<45 \% \text { or } \\
\text { uncontrolled systolic hypertension (>140 or }>160 \mathrm{~mm} \mathrm{Hg} \\
\text { if on } 3 \text { different meds) }\end{array}$ \\
\hline $\begin{array}{l}\text { Böhm et al } \\
2017^{16}\end{array}$ & $\begin{array}{l}\text { ONTARGET/ } \\
\text { TRANSCEND }\end{array}$ & Meta-analysis & 29,179 & $75 \mathrm{mmHg}$ & $\begin{array}{l}\text { Included patients over } 55 y \text { o with CAD, PVD, CVA or } \\
\text { Diabetes. Excluded CCF, ACE intolerance, Syncope, } \\
\text { Planned CABG, Recent PCI, Uncontrolled HTN, heart } \\
\text { transplant, liver disease, other major illness expected to } \\
\text { reduce life expectancy or participation in the trial }\end{array}$ \\
\hline $\begin{array}{l}\text { Flint et al } \\
2019^{25}\end{array}$ & KNPC & $\begin{array}{l}\text { Retrospective, } \\
\text { cohort }\end{array}$ & $1,300,000$ & $80-90 \mathrm{mmHg}$ & $\begin{array}{l}\text { All patients over } 18 y o \text { in } 2009 \text { and enrolled in KPNC for } \\
\text { the } 8 \text { year observation period were included. Excluded } \\
\text { those without a baseline BP reading and at least } 2 \text { further } \\
\text { BP readings during the observation period }\end{array}$ \\
\hline $\begin{array}{l}\text { McEvoy et al } \\
2016^{22}\end{array}$ & ARIC & $\begin{array}{l}\text { Retrospective } \\
\text { analysis of RCT }\end{array}$ & 11,565 & $80 \mathrm{mmHg}$ & $\begin{array}{l}\text { Included patients }>50 \text { yo, with } \mathrm{SBP} \geq 130 \mathrm{mmHg} \text { and CVD } \\
10 \text {-year Risk } \geq 15 \% \text {, or } \mathrm{LVH} \text { by } \mathrm{ECG} \text {, or } \mathrm{ABPi}<0.9 \text {, or } \\
\text { eGFR between } 20 \text { and } 59 \mathrm{~mL} / \mathrm{min} / 1.73 \mathrm{~m}^{2} \text {. Excluded } \\
\text { patients with known CVD or HF }\end{array}$ \\
\hline $\begin{array}{l}\text { Böhm et al } \\
2020^{26}\end{array}$ & EPHESUS & $\begin{array}{l}\text { Retrospective } \\
\text { analysis of RCT }\end{array}$ & 5929 & $70 \mathrm{mmHg}$ & $\begin{array}{l}\text { Included patients with recent } \mathrm{MI} \text { and associated HF or } \\
\text { diabetes. Excluded unstable patients, uncontrolled } \\
\text { hypotension, alcohol abuse, ICD implantation, using } \\
\text { potassium sparing diuretics }\end{array}$ \\
\hline Li et al $2021^{31}$ & $\begin{array}{l}\text { SPRINT/ } \\
\text { ACCORD }\end{array}$ & $\begin{array}{l}\text { Retrospective } \\
\text { analysis of RCT }\end{array}$ & 7515 & $60 \mathrm{mmHg}$ & $\begin{array}{l}\text { SPRINT included patients with known hypertension over } \\
50 \text { yo and increased CV risk. Excluded those diabetes or } \\
\text { CVA }\end{array}$ \\
\hline
\end{tabular}


Temporal Reduction in Diastolic BP Nadir $(\mathrm{mmHg})$

Reported in Observational Analyses of the J Curve

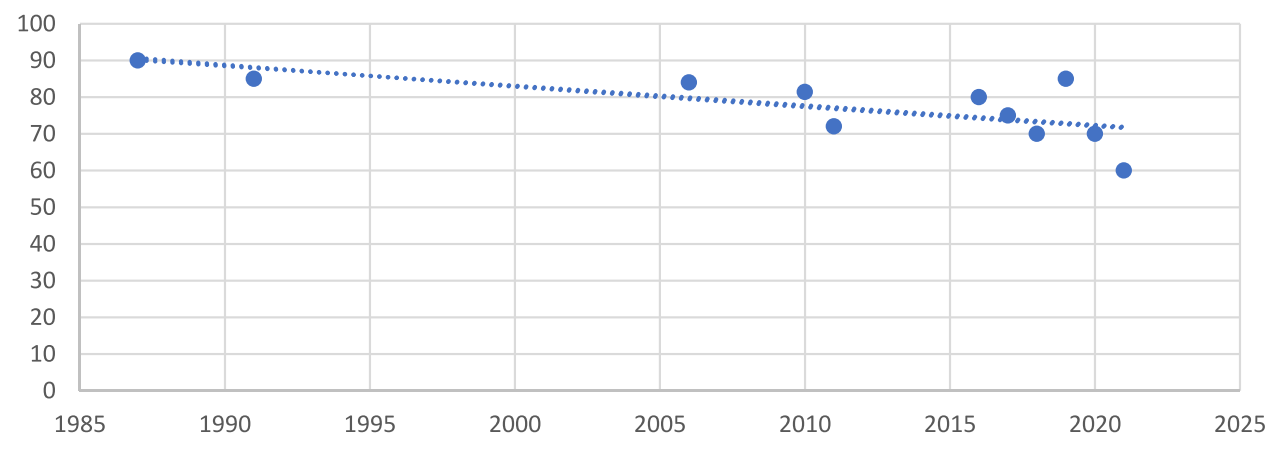

Figure I Selected reports demonstrating a temporal reduction in the nadir of diastolic BP reported in observational analyses testing the diastolic BP J-curve phenomenon.

Further exploring the role of low diastolic BP and coronary artery disease, an analysis in 2016 of the Atherosclerosis Risk in Communities (ARIC) cohort found an increase in subclinical myocardial damage (measured by high-sensitivity troponin I [hsTnI]), CVD events and mortality at low diastolic BP. This finding was independent of baseline anti-hypertensive treatment. The authors concluded that it may be prudent to ensure diastolic BP levels do not fall below $60 \mathrm{~mm} \mathrm{Hg}$ with those patients who had wider pulse pressures thought to be particularly at risk. ${ }^{22}$ A 2016 analysis of the CLARIFY registry which enrolled 22,672 patients with stable coronary artery disease found that a systolic blood pressure of less than $120 \mathrm{~mm} \mathrm{Hg}$ and a diastolic blood pressure of less than $70 \mathrm{~mm} \mathrm{Hg}$ were associated with an increased risk of cardiovascular death, MI and stroke. ${ }^{23}$

In 2017, a meta-analysis published in The Lancet combined the data from the Ongoing Telmisartan Alone and in Combination With Ramipril Global Endpoint Trial (ONTARGET) and Telmisartan Randomised Assessment Study in ACE intolerant subjects with cardiovascular Disease (TRANSCEND) studies to show that diastolic BP less than $70 \mathrm{~mm} \mathrm{Hg}$ was associated with an increased risk for CVD events and MI, but not stroke. ${ }^{16}$ Interestingly, a low systolic BP (120 mm Hg or less) during treatment was associated with increased risk of CVD events other than MI and CVA. This represents one of the few studies to suggest a link between low systolic BP and increased CVD risk. The 2018 post hoc analysis of the dataset from the Treatment of Preserved Cardiac Function Heart Failure with an Aldosterone Antagonist trial (TOPCAT) found that the adjusted risks for CVD events were higher at diastolic BP of less than $70 \mathrm{~mm} \mathrm{Hg}$, especially with a wider pulse pressure. It also found, as expected, adjusted risks for CVD events to be higher at diastolic BP greater than $90 \mathrm{~mm} \mathrm{Hg} .{ }^{24}$ This relationship was present in patients both with and without coronary artery disease.

A retrospective observational study in 2019 of the Kaiser Permanente Northern California (KPNC) cohort showed a linear trend for reducing systolic BP in terms of CVD events but also showed an unadjusted J-curve phenomenon in patients with low diastolic BP. $^{25}$ The J-curve disappeared when adjusted for potential confounders such as age and race. The authors hypothesised that the low incidence of coronary artery disease in the patient cohort may be a contributing factor. A 2020 retrospective analysis of the EPHESUS (Eplerenone Post-Acute Myocardial Infarction Heart Failure Efficacy and Survival Study) dataset showed that patients with left ventricular dysfunction and heart failure following MI, who had low diastolic BP, had increased CVD risk. ${ }^{26}$ It was also observed that, in patients who underwent revascularisation, this association was lost. The authors concluded that low diastolic BP in patients with untreated coronary stenosis are at higher risk of CVD events and that reperfusion appeared to reduce this risk. However, as revascularization was not randomized in the original EPHESUS trial and because revascularization is considered a gold standard, the presence of a J-curve in patients with systolic heart failure after recent MI only among non-revascularised patients could represent the fact that these patients were deemed to be too unwell for the coronary intervention, thereby potentially confounding the results due to selection bias. ${ }^{27}$ 


\section{Evidence from Randomized Controlled Trials}

The 1998 Hypertension Optimal Treatment (HOT) trial is the only randomized clinical trial, which has evaluated the optimum target diastolic blood pressure. ${ }^{28}$ In this trial of 18,790 predominantly primary prevention patients, greater reductions in cardiovascular events were seen in those who had greater reductions in diastolic BP, and appeared to be safe as low as diastolic values of $70 \mathrm{~mm} \mathrm{Hg}$. The trial was limited by the small differences in the blood pressure reduction between the three groups. Despite this, a statistically nonsignificant increase in cardiovascular mortality was seen in those at the lowest level of blood pressure.

Three other RCTs compared cardiovascular outcomes by systolic BP - Strategy of blood pressure intervention in the elderly hypertensive patients (STEP), Systolic Blood Pressure Intervention Trial (SPRINT) and the Action to Control Cardiovascular Risk in Diabetes blood pressure trial (ACCORD-BP). Although none of the three trials titrated antihypertensive therapy to diastolic BP, observations from these studies are nonetheless useful. A 2018 analysis of the SPRINT data demonstrated a J-curve relationship between diastolic BP and cardiovascular events in both the intensive systolic BP goal group $(<120 \mathrm{~mm} \mathrm{Hg})$ and the standard goal group $(<140 \mathrm{~mm} \mathrm{Hg})$, but there was no evidence that the benefit of the intensive systolic BP lowering differed by baseline diastolic BP. This indicates that the diastolic BP "J-curve" relationship does not appear to be casual. ${ }^{6,29}$

The 2021 STEP trial was an RCT comparing cardiovascular outcomes among 8511 older Chinese patients who were randomized to either a target BP of 110 $130 \mathrm{~mm} \mathrm{Hg}$ or $130-150 \mathrm{~mm} \mathrm{Hg}{ }^{5}$ The composite primary outcome was met with an absolute risk reduction of $1.1 \%$ after a median follow-up of 3.34 years. Unsurprisingly, hypotension was higher in the intensive treatment group. However, a sensitivity analysis, which included patients who had a diastolic blood pressure of less than $60 \mathrm{~mm} \mathrm{Hg}$, or a pulse pressure of $60 \mathrm{~mm} \mathrm{Hg}$, demonstrated results that were similar to the primary analysis.

The Action to Control Cardiovascular Risk in Diabetes (ACCORD) trial evaluated the effects of intensive bloodpressure control in type 2 diabetes mellitus. It found no improvement in cardiovascular outcomes apart from decreased stroke in the intensive treatment arm, but this was at the expense of more serious adverse events. ${ }^{30} \mathrm{In}$ a 2021 cohort study of the SPRINT and ACCORD datasets, $\mathrm{Li}$ et al found an association between diastolic BP below $60 \mathrm{~mm} \mathrm{Hg}$ and increased CVD events in patients whose systolic BP was reduced to below $130 \mathrm{~mm} \mathrm{Hg}$. The lowest risk observed in this cohort study was seen in patients with a diastolic BP value between 70 and $80 \mathrm{~mm} \mathrm{Hg}{ }^{31}$ The Stroke in Hypertension Optimal Treatment Trial (ESH-CHLSHOT), which aimed to evaluate the optimum blood pressure target in patients with a history of stroke or transient ischemic attack, was unfortunately terminated early in 2020 due to difficulty in enrolling post-stroke patients. ${ }^{32}$

\section{Regional Circulation and Susceptibility to Low Diastolic Blood Pressure}

The J-curve phenomenon has roots in a biologically plausible mechanism. As blood pressure falls, a threshold is reached, beyond which perfusion of important organs such as the heart, brain and kidneys becomes inadequate. This threshold varies between organs and between individuals as a result of arterial stenosis, temporal fluctuations in blood pressure, and variation in regional circulation and autoregulation of key organs. ${ }^{33}$ When considering myocardial perfusion, diastolic BP is particularly important given coronary artery filling primarily occurs during diastole (Figure 2). This is especially true for patients with obstructive coronary artery disease or left ventricular hypertrophy, as these individuals are more susceptible to the effects of a reduced coronary perfusion pressure. ${ }^{34}$ This unique regional circulation contrasts with cerebral and renal perfusion, which consistently appear less susceptible to lower diastolic BP. This helps to explain the increased rates of MI, without an increase in stroke, associated with lower diastolic BP, seen in the ARIC, INVEST and ONTARGET/TRANSCEND analyses discussed above. Similar findings were seen in analyses of the ACCORD-BP and STEP trials. A 2011 analysis of the ONTARGET RCT, which demonstrated telmisartan to be noninferior to ramipril, found that blood pressure target attainment was associated with cerebrovascular and renal protection, but did not increase cardiac protection. ${ }^{35,36}$ Park et al provided a notable exception to this consistent theme when they reported an increased risk of stroke with diastolic $\mathrm{BP}<70 \mathrm{~mm} \mathrm{Hg}$ and pulse pressure $>60 \mathrm{~mm} \mathrm{Hg}$ in patients who had sustained a recent non-cardioembolic stroke. $^{37}$ 
A

B
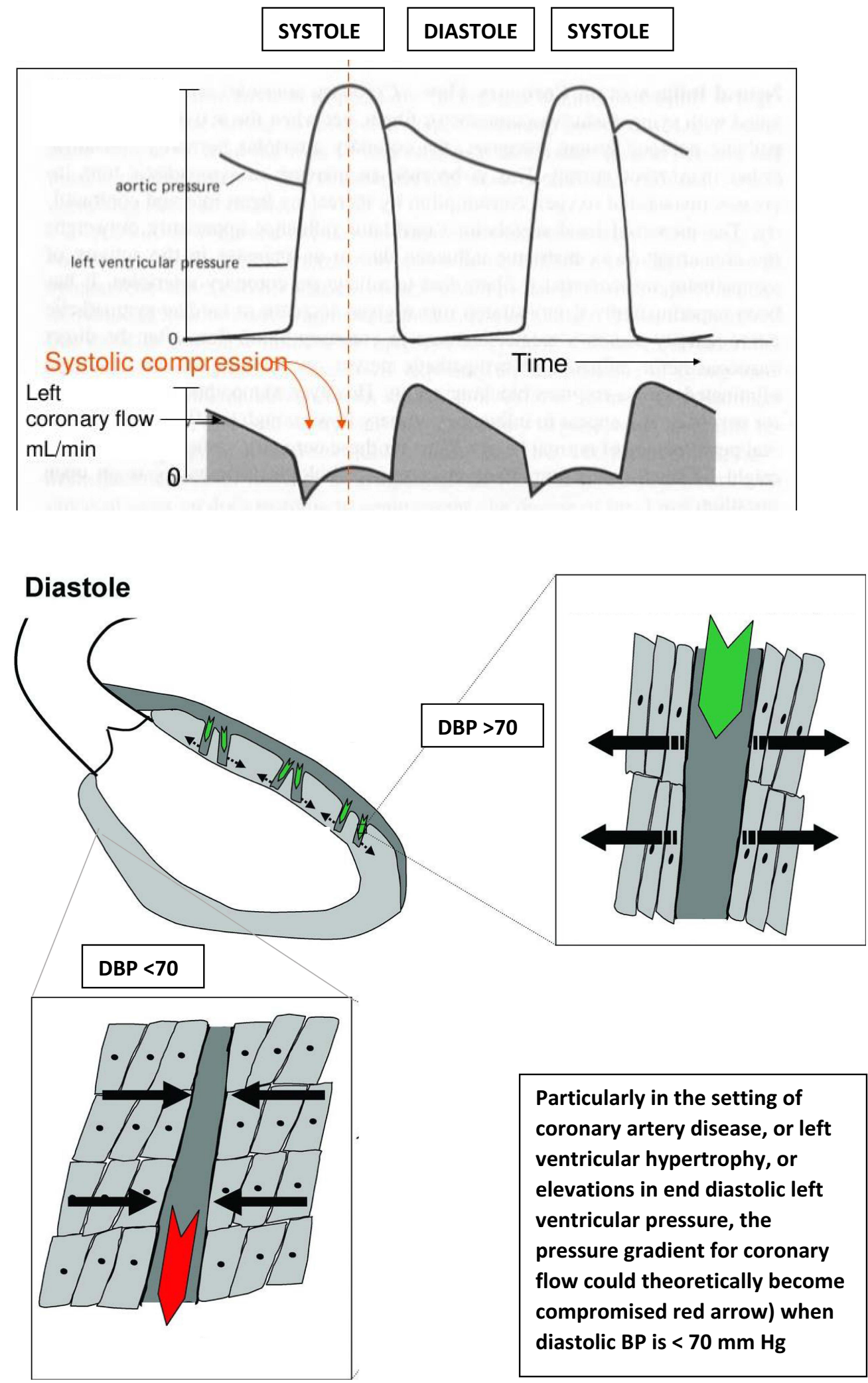

Figure 2 Hypothesised pathophysiological mechanism underpinning the diastolic BP J-curve. (A) Coronary blood flow occurs only during diastole; hence, diastolic BP is an important determinant of coronary perfusion pressure. (B) Particularly in the setting of coronary artery disease, or left ventricular hypertrophy, or elevations in end diastolic left ventricular pressure, the pressure gradient for coronary flow could theoretically become compromised red arrow when diastolic BP is $<70 \mathrm{~mm} \mathrm{Hg}$. 


\section{Current J-Curve Guideline Recommendations}

Observational studies have suggested different nadirs for the J-curve ranging from 60 up to $85 \mathrm{~mm} \mathrm{Hg} .{ }^{14}$ Prompted by concerns regarding a J-curve, the 2018 ESC guidelines provided a class I recommendation to target a systolic BP $\leq 130 \mathrm{~mm} \mathrm{Hg}$ (but not $<120 \mathrm{~mm} \mathrm{Hg}$ ) and a diastolic BP $<80 \mathrm{~mm} \mathrm{Hg}$ (but not $<70 \mathrm{~mm} \mathrm{Hg}$ ) in particularly susceptible hypertensive patients such as those with coronary artery disease or diabetes mellitus. ${ }^{9}$ Specific ranges are also provided for those with left ventricular hypertrophy and those $\geq 65$ years old. Notably, the 2021 ESC Prevention guideline similarly provided lower limits to systolic BP targets, but omitted any lower diastolic BP threshold, instead recommending that all should have a diastolic BP $<80 \mathrm{~mm} \mathrm{Hg.}{ }^{4}$ By contrast, current $\mathrm{AHA}$ guidelines do not suggest a lower limit of target $\mathrm{BP}^{2}$

\section{Mendelian Randomization as a Strategy to Evaluate Causality}

The totality of the evidence discussed thus far confirms that the relationship between diastolic blood pressure and CVD events is J-shaped. However, the causality of this relationship is unclear - particularly because the strength of this J-curve association is vulnerable to adjustment for confounding factors, which include arterial stiffness, comorbid conditions, sarcopenia, and age. The diastolic BP J-curve is particularly observed in older patients with hypertension and wider pulse pressures due to increased arterial stiffness. ${ }^{8,33}$ Arterial stiffness is a well-recognised independent risk factor for CVD events. ${ }^{38}$ Other comorbid states such as coronary artery disease, diabetes, heart failure and atrial fibrillation all increase risk of CVD events and all have potential effects on blood pressure and treatments. Given the complexity in accounting for these linked conditions, there is a potential for reverse causality in the above studies. Knowledge of the fact that diastolic BP trends downwards as we age further adds to this complexity, as it makes bias towards more elderly patients difficult to exclude. ${ }^{39}$ Mendelian randomization has emerged as a research method, with which associations noted in traditional observational studies can be evaluated.

Mendelian randomisation (MR) is a research method that can provide evidence about possible causal relations between modifiable risk factors and disease, using genetic variants as natural experiments. ${ }^{40}$ It is thought MR studies are less likely to be affected by confounding or reverse causation compared to conventional observational studies provided a number of assumptions are met, as they mimic the biological link between a proposed exposure and disease. ${ }^{41}$ Genome-wide association studies are used to identify single nucleotide polymorphisms, which place a person at risk. These are then are gathered to make an allele score - effectively a single instrumental variable that can be used to predict the risk factor in the MR analysis. It is also generally accepted that Mendelian randomisation studies, which evaluate innate parameters using a more causal framework, do tend to provide results that align quite well with RCT data, suggesting that the CVD effects of innate (treatment naïve) diastolic BP and on-treatment diastolic BP are similar.

In 2021, two studies using linear and nonlinear MR techniques further explored the association between diastolic BP and CVD events. ${ }^{42,43}$ The first of these studies was performed on five large population cohorts to more definitively establish the causal direction and shape of the relationship between diastolic BP and CVD, particularly MI. ${ }^{42}$ The second MR analysis was performed using MR methods within the comprehensive UK Biobank resource to study genetically proxied systolic and diastolic BP with incident CVD. ${ }^{43}$ Both analyses found that the effect of diastolic BP on CVD was linear, with no genetic evidence for a J- or U-shaped association between diastolic BP and CVD outcomes identified. There was also no evidence of a nonlinear genetic effect of systolic BP on CVD. The MR study shows the effect of a lifelong reduction in blood pressure on the primary prevention of CVD.

\section{Conclusion}

In the absence of adequate randomized controlled trial data to ascertain the optimal target diastolic BP, we have had to rely on an assortment of observational data. These data have, to date, clearly demonstrated that individuals with very low diastolic BP are at increased cardiovascular risk. Some individuals such as elderly patients with stiff arterial vessels, and those with underlying coronary artery disease, diabetes mellitus, and left ventricular hypertrophy, are at particularly high risk. However, Mendelian randomization data and post-hoc analyses of the SPRINT and STEP trials indicate that low diastolic blood pressure is not necessarily a cause of the increased risk of CVD it accompanies, but rather that the increased risk is mediated confounding factors or reverse causation.

In summary, how might you approach a hypertensive patient who comes to your clinic with a low diastolic blood pressure? First, interpret this as a poor prognostic sign from 
a cardiovascular perspective, which should prompt you to optimize them from a prevention standpoint. Second, discuss the risks and benefits of guideline-recommended BP goals with the patient and consider whether a more lenient blood pressure goal might be indicated; for example, are they frail or do they have chronic kidney disease. Third, up-titrate antihypertensive therapy as you deem appropriate, particularly for individuals with persistent elevations in systolic BP, without worrying as much about dropping the diastolic BP too low.

\section{Main Learning Points}

1. Numerous observational studies have documented a J-curve association between diastolic blood pressure (DBP) and adverse cardiac events, with increased risk for events observed at very high and very low levels of DBP.

2. This finding may deter physicians from more intensive treatment of systolic hypertension in the setting of low DBP

3. More recent analyses using both Mendelian randomisation and post-hoc examination of the SPRINT and ACCORD trials suggest that the association of low DBP with adverse cardiac events is due to confounding or reverse causation and, thus, the diastolic BP J-curve does not appear to be a causal phenomenon.

4. These findings suggest that antihypertensives should not be withheld or reduced in those with systolic hypertension and low DBP.

\section{Disclosure}

The authors report no conflicts of interest in this work.

\section{References}

1. Mills KT, Bundy JD, Kelly TN, et al. Global disparities of hypertension prevalence and control: a systematic analysis of population-based studies from 90 countries. Circulation. 2016;134(6):441-450. doi:10.1161/CIRCULATIONAHA.115.018912

2. Carey RM, Whelton PK. 2017 ACC/AHA Hypertension Guideline Writing Committee. Prevention, detection, evaluation, and management of high blood pressure in adults: synopsis of the 2017 American College of Cardiology/American Heart Association Hypertension Guideline. Ann Intern Med. 2018;168(5):351-358. doi:10.7326/M17-3203

3. Kompaniyets L, Pennington AF, Goodman AB, et al. Underlying medical conditions and severe illness among 540,667 adults hospitalized with COVID-19, March 2020-March 2021. Prev Chronic Dis. 2021;18:E66. doi:10.5888/pcd18.210123

4. Visseren FLJ, Mach F, Smulders YM, et al. 2021 ESC guidelines on cardiovascular disease prevention in clinical practice: developed by the Task Force for cardiovascular disease prevention in clinical practice with representatives of the European Society of Cardiology and 12 medical societies with the special contribution of the European Association of Preventive Cardiology (EAPC). Eur Heart J. 2021; (ehab484). doi:10.1093/eurheartj/ehab484
5. Zhang W, Zhang S, Deng Y, et al. Trial of intensive blood-pressure control in older patients with hypertension. $N$ Engl $J$ Med. 2021;385:1268-1279. doi:10.1056/NEJMoa2111437

6. SPRINT Research Group. A randomized trial of intensive versus standard blood-pressure control. $N$ Engl $J$ Med. 2015;373 (22):2103-2116. doi:10.1056/NEJMoa1511939

7. Lewington S, Clarke R, Qizilbash N, Peto R, Collins R; Prospective Studies Collaboration. Age-specific relevance of usual blood pressure to vascular mortality: a meta-analysis of individual data for one million adults in 61 prospective studies. Lancet Lond Engl. 2002;360(9349):1903-1913. doi:10.1016/s01406736(02)11911-8

8. Whelton SP, McEvoy JW, Shaw L, et al. Association of normal systolic blood pressure level with cardiovascular disease in the absence of risk factors. JAMA Cardiol. 2020;5(9):1011-1018. doi:10.1001/jamacardio.2020.1731

9. Williams B, Mancia G, Spiering W, et al. 2018 ESC/ESH Guidelines for the management of arterial hypertension. Eur Heart J. 2018;39 (33):3021-3104. doi:10.1093/eurheartj/ehy339

10. Cicero AFG, Fogacci F, Borghi C. Cost-effectiveness analysis of different hypertension management strategies. Intern Emerg Med. 2020;15(2):181-182. doi:10.1007/s11739-019-02153-w

11. Rahman F, McEvoy JW. The J-shaped curve for blood pressure and cardiovascular disease risk: historical context and recent updates. Curr Atheroscler Rep. 2017;19(8):34. doi:10.1007/s11883-0170670-1

12. Kjeldsen SE, Oparil S, Narkiewicz K, Hedner T. The J-curve phenomenon revisited again: SPRINT outcomes favor target systolic blood pressure below $120 \mathrm{mmHg}$. Blood Press. 2016;25(1):1-3. doi:10.3109/08037051.2016.1096564

13. Mancia G, Grassi G. Aggressive blood pressure lowering is dangerous: the J-curve: pro side of the argument. Hypertens Dallas Tex. 2014;63(1):29-36. doi:10.1161/01.hyp.0000441190. 09494.e9

14. Messerli FH, Panjrath GS. The J-curve between blood pressure and coronary artery disease or essential hypertension: exactly how essential? J Am Coll Cardiol. 2009;54(20):1827-1834. doi:10.1016/ j.jacc.2009.05.073

15. Ettehad D, Emdin CA, Kiran A, et al. Blood pressure lowering for prevention of cardiovascular disease and death: a systematic review and meta-analysis. Lancet Lond Engl. 2016;387(10022):957-967. doi:10.1016/S0140-6736(15)01225-8

16. Böhm M, Schumacher H, Teo KK, et al. Achieved blood pressure and cardiovascular outcomes in high-risk patients: results from ONTARGET and TRANSCEND trials. Lancet. 2017;389 (10085):2226-2237. doi:10.1016/S0140-6736(17)30754-7

17. Cruickshank JM, Thorp JM, Zacharias FJ. Benefits and potential harm of lowering high blood pressure. Lancet Lond Engl. 1987;329(8533):581-584. doi:10.1016/s0140-6736 (87)90231-5

18. Farnett L, Mulrow CD, Linn WD, Lucey CR, Tuley MR. The J-curve phenomenon and the treatment of hypertension. Is there a point beyond which pressure reduction is dangerous? JAMA. 1991;265 (4):489-495. doi:10.1001/jama.1991.03460040065031

19. Messerli FH, Mancia G, Conti CR, et al. Dogma disputed: can aggressively lowering blood pressure in hypertensive patients with coronary artery disease be dangerous? Ann Intern Med. 2006;144 (12):884-893. doi:10.7326/0003-4819-144-12-200606200-00005

20. LaRosa JC, Grundy SM, Waters DD, et al. Intensive lipid lowering with atorvastatin in patients with stable coronary disease. $N$ Engl $J$ Med. 2005. doi:10.1056/NEJMoa050461

21. Bangalore S, Messerli FH, Wun CC, et al. J-curve revisited: an analysis of blood pressure and cardiovascular events in the Treating to New Targets (TNT) trial. Eur Heart J. 2010;31(23):2897-2908. doi:10.1093/eurheartj/ehq328 
22. McEvoy JW, Chen Y, Rawlings A, et al. Diastolic blood pressure, subclinical myocardial damage, and cardiac events: implications for blood pressure control. J Am Coll Cardiol. 2016;68(16):1713-1722. doi:10.1016/j.jacc.2016.07.754

23. Vidal-Petiot E, Ford I, Greenlaw N, et al. Cardiovascular event rates and mortality according to achieved systolic and diastolic blood pressure in patients with stable coronary artery disease: an international cohort study. Lancet Lond Engl. 2016;388(10056):2142-2152. doi:10.1016/S0140-6736(16)31326-5

24. Tsujimoto T, Kajio H. Low diastolic blood pressure and adverse outcomes in heart failure with preserved ejection fraction. Int J Cardiol. 2018;263:69-74. doi:10.1016/j.ijcard.2018.04.031

25. Flint AC, Conell C, Ren X, et al. Effect of systolic and diastolic blood pressure on cardiovascular outcomes. $N$ Engl J Med. 2019;381 (3):243-251. doi:10.1056/NEJMoa1803180

26. Böhm M, Ferreira JP, Mahfoud F, et al. Myocardial reperfusion reverses the J-curve association of cardiovascular risk and diastolic blood pressure in patients with left ventricular dysfunction and heart failure after myocardial infarction: insights from the EPHESUS trial. Eur Heart J. 2020;41(17):1673-1683. doi:10.1093/eurheartj/ehaa132

27. Liew CH, McEvoy JW. The diastolic blood pressure J-curve remains an observational research phenomenon that has not yet been proven as causal and should not be used to make invasive treatment decisions. Eur Heart J. 2020;41(44):4284-4285. doi:10.1093/eurheartj/ehaa627

28. Hansson L, Zanchetti A, Carruthers SG, et al. Effects of intensive blood-pressure lowering and low-dose aspirin in patients with hypertension: principal results of the Hypertension Optimal Treatment (HOT) randomised trial. HOT Study Group. Lancet Lond Engl. 1998;351(9118):1755-1762. doi:10.1016/s0140-6736(98)04311-6

29. Beddhu S, Chertow GM, Cheung AK, et al. Influence of baseline diastolic blood pressure on effects of intensive compared to standard blood pressure control. Circulation. 2018;137(2):134-143. doi:10. 1161/CIRCULATIONAHA.117.030848

30. ACCORD Study Group. Effects of combination lipid therapy in type 2 diabetes mellitus. $N$ Engl J Med. 2010;362(17):1563-1574. doi:10.1056/NEJMoa1001282

31. Li J, Somers VK, Gao X, et al. Evaluation of optimal diastolic blood pressure range among adults with treated systolic blood pressure less than $130 \mathrm{~mm}$ Hg. JAMA Netw Open. 2021;4(2):e2037554. doi:10.10 01/jamanetworkopen.2020.37554

32. Liu L, Mancia G. Termination of the ESH-CHL-SHOT trial. J Hypertens. 2020;38(12):2542-2543. doi:10.1097/HJH.00000000000 02660
33. Kang YY, Wang JG. The J-curve phenomenon in hypertension. Pulse. 2016;4(1):49-60. doi:10.1159/000446922

34. Harrison DG, Florentine MS, Brooks LA, Cooper SM, Marcus ML. The effect of hypertension and left ventricular hypertrophy on the lower range of coronary autoregulation. Circulation. 1988;77 (5):1108-1115. doi:10.1161/01.CIR.77.5.1108

35. Yusuf S, Teo KK, Pogue J, Dyal L, Copland I, Schumacher H. coll. Telmisartan, ramipril, or both in patients at high risk for vascular events. $N$ Engl J Med. 2008. doi:10.1056/NEJMoa0801317

36. Mancia G, Schumacher H, Redon J, et al. Blood pressure targets recommended by guidelines and incidence of cardiovascular and renal events in the ongoing telmisartan alone and in combination with ramipril global endpoint trial (ONTARGET). Circulation. 2011;124(16):1727-1736. doi:10.1161/CIRCULATIONAHA.110.00 8870

37. Park JH, Ovbiagele B. Post-stroke diastolic blood pressure and risk of recurrent vascular events. Eur J Neurol. 2017;24(11):1416-1423. doi:10.1111/ene.13411

38. Franklin SS, Lopez VA, Wong ND, et al. Single versus combined blood pressure components and risk for cardiovascular disease. Circulation. 2009;119(2):243-250. doi:10.1161/CIRCULATIONAHA. 108.797936

39. Stefanie L, En TL, Panniyammakal J, Linsay M, Dominiczak Anna F, Sandosh P. Diastolic blood pressure J-curve phenomenon in a tertiary-care hypertension clinic. Hypertension. 2019;74(4):767-775. doi:10.1161/HYPERTENSIONAHA.119.12787

40. Davies NM, Holmes MV, Davey Smith G. Reading Mendelian randomisation studies: a guide, glossary, and checklist for clinicians. BMJ. 2018;362:k601. doi:10.1136/bmj.k601

41. Smith GD, Ebrahim S, Lip S, et al. "Mendelian randomization": can genetic epidemiology contribute to understanding environmental determinants of disease? Int $J$ Epidemiol. 2003;32(1):1-22. doi:10. 1093/ije/dyg070

42. Arvanitis M, Qi G, Bhatt DL, et al. Linear and nonlinear Mendelian randomization analyses of the association between diastolic blood pressure and cardiovascular events: the J-curve revisited. Circulation. 2021;143(9):895-906. doi:10.1161/CIRCULATIONAHA.120.049 819

43. Malik R, Georgakis MK, Vujkovic M, et al. Relationship between blood pressure and incident cardiovascular disease: linear and nonlinear Mendelian randomization analyses. Hypertens Dallas Tex. 2021;77(6):2004-2013. doi:10.1161/HYPERTENSIONAHA.120.16 534
Integrated Blood Pressure Control

\section{Publish your work in this journal}

Integrated Blood Pressure Control is an international, peer-reviewed open-access journal focusing on the integrated approach to managing hypertension and risk reduction. Treating the patient and comorbidities together with diet and lifestyle modification and optimizing healthcare resources through a multidisciplinary team approach constitute key features of the journal. This journal is indexed on
American Chemical Society's Chemical Abstracts Service (CAS) The manuscript management system is completely online and includes a very quick and fair peer-review system, which is all easy to use. Visit http://www.dovepress.com/testimonials.php to read real quotes from published authors. 